\title{
Substanțele psihoactive noi şi riscurile consumului la copii şi adolescenți
}

\begin{abstract}
Viorela Nițescu
Spitalul Clinic de Urgență pentru Copii „Grigore Alexandrescu“, București, România

REZUMAT

Conform definiției stabilite de Monitorul European pentru Droguri şi Toxicomanie (European Monitoring Centre for Drugs and Drug Addiction - EMCDDA), o „substanță psihoactivă nouă este considerată orice substanță narcotică sau psihotropă în formă pură sau în preparate, care nu este controlată prin Convențiile privitoare la droguri ale Națiunilor Unite și care reprezintă o amenințare la adresa sănătății umane comparabilă cu cea realizată de substanțele înregistrate în aceste convenții considerate substanțe ilicite“ (1). Au fost descrise 4 clase principale de substanțe psihoactive noi canabinoidele sintetice, catinonele sintetice, halucinogenele naturale şi piperazinele. Canabinoidele sintetice sunt agoniști sintetici ai receptorilor canabinoizi, constituind un grup de substanțe de sinteză care mimează efectele $\Delta 9$ tetrahidrocanabinolului (THC), principalul produs al canabisului răspunzător de efectele psihoactive ale acestuia (4). Simptomele intoxicației sunt asemănătoare cu cele ale intoxicației cu canabis, dar mai severe, tabloul clinic cuprinzând cel mai frecvent: agitație, greață, palpitații (9). Catinonele sintetice sunt compuși derivați din catinonă - principalul constituent al plantei Catha edulis, cunoscută sub denumirea de KHAT (12). Cei mai cunoscuți reprezentanți ai grupului sunt: metcatinona, mefedrona (4-metilcatinona), metilona, metedrona, naftilpirovalerona şi numeroşi substituenți ai MDMA (Ectasy): MDAI, MMAI, MDMAT. Simptomele intoxicației sunt asemănătoare, dar mai severe cu cele ale intoxicațiilor cu amfetamine, metamfetamine sau cocaină, în funcție de tipul substanței $(2,12)$. Halucinogenele sunt substanțe care în doze mici au ca efect principal alterarea percepției, gândirii şi stării de spirit, cu păstrarea lucidității, alături de efecte minore asupra memoriei şi orientării $(23,24)$. Cele mai cunoscute halucinogene naturale sunt: salvinorin A, psilocibina și psilocina, muscimolul şi acidul ibotenic. Piperazinele sunt compuși sintetici similari cu amfetaminele, dar cu efecte mai slabe.Cele mai cunoscute sunt: benzilpiperazinele şi fenilpiperazinele (28).

Concluzii. Consumul ocazional care poate duce la intoxicații acute sau consumul cronic de substanțe psihoactive noi reprezintă o problemă importantă de sănătate, ocupând un loc care nu trebuie neglijat în patologia adolescenților şi tinerilor.
\end{abstract}

Cuvinte cheie: substanţe psihoactive noi, canabinoide, catinone, halucinogene, piperazine

\section{INTRODUCERE}

Conform definiției stabilite de Monitorul European pentru Droguri şi Toxicomanie (European Monitoring Centre for Drugs and Drug Addiction EMCDDA), o „substanță psihoactivă nouă este considerată orice substanță narcotică sau psihotropă în formă pură sau în preparate, care nu este controlată prin Convențiile privitoare la droguri ale Națiunilor Unite și care reprezintă o amenințare la adresa sănătații umane comparabilă cu cea realizată de substanțele înregistrate în aceste convenții considerate substanțe ilicite“" (1).

Sunt conținute în aşa-numitele ,produse legale“ "legal highs", care sunt vândute pe internet, pe stradă sau în unele țări chiar în magazine autorizate, aşa-numitele "head and smart" shops. Aceste ,produse legale" sunt amestecuri de plante, pulberi, pastile, sare de baie, îngrăşăminte de plante, lacuri de curățat etc., invariabil fiind etichetate în prezent nefiind destinate consumului uman $(2,3)$.

Consumul acestor substanţe de către adolescenți și tineri a devenit un fenomen, așa-numitul fenomen "spice", începând de la mijlocul anului 2000, atingând un vârf în perioada 2008-2012, ulterior înregistrând o scădere semnificativă, dar menținându-se la un nivel constant al consumului ca urmare a reglementărilor legislative din intreaga Uniune Europeană.

În țara noastră, primele cazuri de intoxicații cu substanțe psihoactive noi au fost înregistrate la sfârşitul anului 2009, odată cu apariția în număr mare în întreaga țară a magazinelor care vindeau aceste „produse legale“. Termenul folosit iniţial atât de publicul larg, cât şi de specialiști pentru denumirea acestor produse a fost de „etnobotanice“, termen la care s-a renunțat, ulterior fiind înlocuit de cel de „substanțe psihoactive noi“". Vârful consumului și, în consecință, şi al intoxicațiilor cu acest tip de substanțe a fost atins 
în perioada 2010-2012, când ponderea lor în cadrul consumului și al intoxicațiilor cu substanțe de abuz era majoritară, iar fenomenul luase o amploare deosebită, constituind o amenințare foarte serioasă la adresa sănătății și vieții adolescenților şi tinerilor. Ca urmare a acestui fapt, în anul 2011, autoritățile române, urmând exemplul majorității țărilor europene, au interzis prin lege comercializarea și consumul acestor tipuri de produse, rezultatul fiind o scădere semnificativă atât a consumului, cât şi a intoxicațiilor, care s-au stabilizat ulterior la un nivel constant. Acest lucru este relevat de statisticile efectuate în Centrul Național Antitoxic Pediatric din Spitalul Clinic de Urgență pentru Copii din București, care au arătat că, în perioada 2010-2012, intoxicațiile acute cu substanțe psihoactive noi reprezentau $88,42 \%$ din totalul intoxicațiilor acute cu substanțe de abuz, în timp ce, începând cu anul 2013, incidența lor a scăzut semnificativ, în perioada 2013-2017 reprezentând numai $12,6 \%$ din totalul intoxicațiilor acute cu substanțe de abuz.

\section{CLASIFICARE}

$\mathrm{Au}$ fost descrise 4 clase principale de substanțe psihoactive noi:

- canabinoide sintetice (conținute în amestecuri de plante)

- catinone sintetice (conținute în diverse pulberi de tip sare de baie)

- halucinogene naturale

- piperazine (conținute în tablete sau capsule)

\section{CANABINOIDELE SINTETICE}

Canabinoidele sintetice sunt agoniști sintetici ai receptorilor canabinoizi, constituind un grup de substanțe de sinteză care mimează efectele $\Delta 9$ tetrahidrocanabinolului (THC), principalul produs al canabisului răspunzător de efectele psihoactive ale acestuia (4). Aceste substanțe sintetice se leagă de receptorii canabinoizi, realizând efecte THC-like, dar cu intensitate și durată mai mare (5). Reprezintă grupul cel mai mare de substanțe psihoactive noi monitorizate de Observatorul European pentru Droguri și Toxicomanie prin sistemul de avertizare timpurie: dintre cele 731 de substanțe psihoactive noi monitorizate de EMCDDA prin sistemul de alertă timpurie, 190 erau canabinoide sintetice, în fiecare an fiind raportate în jur de 50 de substanțe noi (6). Principalele țări de provenienţă sunt China şi India (7), dar în ultimii ani au fost descoperite şi pe teritoriul Uniunii Europene câteva mici laboratoare artizanale în Polonia și Danemarca (6).
Din punct de vedere chimic, canabinoidele sintetice conţin un lanţ lateral cu patru până la nouă atomi de carbon saturaţi. Componentul comun al acestor produşi este reprezentat de $\Delta 9$ tetrahidrocanbinol.

Din punctul de vedere al structurii chimice, au fost descrise şapte categorii majore de canabinoide sintetice:

1. Naftoilindoli - ex. JWH018, JWH073, JWH398

2. Naftilmetilindoli

3. Naftoilpiroli

4. Naftilmetilindeni

5. Fenilacetilindoli - ex. JWH-250

6. Ciclohexifenoli-CP47,497

7. Canabinoidele clasice - ex HU-210

Numele canabinoidelor sintetice este legat fie de modul de descoperire, fie de structura chimică (2). De exemplu, primul cannabinoid sintetic, JW018, provine de la numele lui John W. Huffman, care i-a descris structura chimică. În alte cazuri, numele provin de la numele institutelor unde au fost sintetizate pentru prima oară, HU - Hebrew University, CP - Carl Pfeizer. În ultimii ani, datorită numărului din ce în ce mai mare de compuși sintetizați, numele au fost alocate legat de structura chimică, de exemplu: APICA -adamantil-pentil-indol carboxamida sau APINACA - N1adamantil-1-pentil-1-indazol 3-carboxamida.

Efectele consumului de canabinoide sintetice sunt următoarele:

- relaxare, spontaneitate, percepția de trecere lentă a timpului, amețeli

- alterarea senzoriului, dificultăți în executarea unor funcții mentale complexe precum învățarea, comunicarea verbală sau memoria (8)

- creșterea apetitului, gura uscată, hiperemie conjunctivală, ochi strălucitori

- tahicardie, transpirații, diminuarea coordonării mișcărilor

Consumul repetat poate duce la fenomenul de dependență (adicție).

Simptomele intoxicației sunt asemănătoare cu cele ale intoxicaţiei cu canabis, dar mai severe, tabloul clinic cuprinzând cel mai frecvent: agitație, greață, palpitații (9).

Mai puţin comune sunt: accidentul vascular cerebral, convulsiile, infarctul miocardic, distrugeri ale fibrei musculare, afectarea renală, vărsături incoercibile, psihoză și chiar deces $(10,11)$.

Una dintre cele mai frapante caracteristici ale consumului de canabinoide sintetice este apariţia unor intoxicații în masă, intoxicații ce apar la sute de persoane într-o perioadă scurtă de timp. De exemplu, intoxicaţia în masă cu MDMB-FUBINACA descrisă 
în Rusia în 2014 și intoxicația cu ADB-FUBINACA în SUA în 2015 sau intoxicația cu produsul denumit „Mocarz“ în Polonia în 2015.

\section{CATINONELE SINTETICE}

Sunt compuși derivați din catinona (fig 4) - principalul constituent al plantei Catha edulis, cunoscută sub denumirea de KHAT (12). Din punct de vedere chimic, acestea sunt analogi $\beta$-keto( $\beta \mathrm{k})$ ai fentilaminei (fig 5), fiind identificați până în prezent peste 138 de compuși $(6,13)$.

Cei mai cunoscuți reprezentanți ai grupului sunt:

- metcatinona - prima catinona sintetică apărută pe piața drogurilor ilicite

- mefedrona (4-metilcatinona), cunoscută sub numele de stradă Miaow, M-Cat, este cel mai des utilizată din grupul catinonelor sintetice $(6,14)$

- metilona - are structură asemănătoare cu MDMA (Ectasy) și este cunoscută sub numele de stradă Top-Cat (12)

- metedrona

- naftilpirovalerona - substanță similară pirovaleronei (2)

- numeroși substituenți ai MDMA (Ectasy): MDAI, MMAI, MDMAT

Catinonele sintetice se prezintă sub formă de pulbere albă sau maronie, amorfă sau cristalină, în amestecuri diferite vândute ca „îngrăşământ de plante“, „sare de baie" sau reactivi chimici (15). Mai rar, se găsesc sub formă de capsule sau tablete fiind vândute drept Ectasy.

Efectele consumului depind de tipul substanței, fiind deci asemănătoare cu cele ale amfetaminelor, metamfetaminelor sau cocainei. Pot fi consumate atât sub formă de capsule, cât şi prizate $(16,17)$. De exemplu, mefedrona este atât prizată, cât și consumată în capsule, în timp ce metilona este consumată predominant sub formă de capsule şi rareori prizată, deoarece pulberea este foarte iritantă pentru mucoasa nazală (18).

Simptomele intoxicației sunt asemănătoare, dar mai severe cu ce ale intoxicațiilor cu amfetamine, metamfetamine sau cocaină în funcție de tipul substanței $(2,12)$.

Astfel, au fost descrise:

- efecte simpaticomimetice similare amfetaminelor și derivaților acestora $(19,20)$

- efecte cardiovasculare severe: tahicardie, aritmii, tulburări circulatorii (21)

- efecte neurologice: convulsii

- hipertermia care este un efect tipic catinonelor sintetice
Primele catinone sintetice au aceeași neutotoxicitate $\mathrm{cu}$ amfetaminele şi metamfetaminele, în timp ce compușii mai noi (MDAI, MDAT) sunt mai puțin neurotoxici comparativ cu MDMA (Ectasy) fiind din acest motiv preferate de consumatori (22).

\section{HALUCINOGENELE NATURALE}

Halucinogenele sunt substanţe care în doze mici au ca efect principal alterarea percepției, gândirii şi stării de spirit, cu păstrarea lucidității, alături de efecte minore asupra memoriei şi orientării $(23,24)$. În ciuda numelui, aceste substanţe rareori produc halucinații adevarate.

Halucinogenele cuprind trei clase principale: indolalchil amine sau triptamine (ex. LSD, psilocina şi psilocibina), fentilamine (mescaline şi metilendioximetamfetamina - MDMA) şi canabinoidele.

Cele mai cunoscute halucinogene naturale sunt:

- salvinorinul A

- psilocibina şi psilocina

- muscimolul şi acidul ibotenic

Salvinorinul A este cel mai puternic halucinogen natural cunoscut până în prezent, fiind active la doze foarte mici de ordinul a $200 \mu \mathrm{g}$. A fost identificat în planta Salvia divinorum, care face parte din familia mentei și care este foarte asemănătoare, dar nu identică cu planta utilizată în alimentație Salvia officinalis (23). Este un agonist al receptorilor opioizi $\mathrm{k}$ și produce efecte halucinogene de tip psihedelic $(2,25)$.

Fosfatul esteric de psilocibină este conţinut în ciupercile halucinogene: Psylocibe, Conocybe și Hygrocibe. In vivo este hidrolizat în psilocină, acesta având efecte asemănătoare cu serotonina $(26,27)$.

Muscimolul şi acidul ibotenic sunt compuşi identificați în ciuperca Amanita muscaria. Sunt analogi ai acidului Y-hidroxibutiric (GHB).

\section{PIPERAZINELE}

Piperazinele sunt compuși sintetici similari cu amfetaminele, dar cu efecte mai slabe.

$\mathrm{Au}$ fost descrise două categorii majore de piperazine: benzilpiperazinele şi fenilpiperazinele (28).

Cea mai cunoscută benzilpiperazină este benzilpiperazina A2, având ca nume de stradă Legal X, Pep X.

Fenilpiperazinele constituie un grup mai numeros, cei mai importanți reprezentanți fiind: 1,3 clorpiperazina - mCPP, 1-3 trifluorometifenilpiperazina (TFMPP) şi 1,4 metoxifenilpiperazina (MeOPP).

Piperazinele se găsesc sub formă de capsule sau tablete.

Efectele consumului sunt similare cu cele ale MDMA (Ectasy) (29). 
Simptomele intoxicației sunt următoarele:

- durere epigastrică, greață, tremor

- tulburări de somn, confuzie, iritabilitate, stare de rău convulsiv $(30,31)$

- sindrom serotoninergic, tipic pentru mCPP: anxietate, migrenă, atacuri de panică.

\section{ALTE SUBSTANȚE PSIHOACTIVE NOI}

Din cauza apariției numeroase de la an la an, au apărut şi multe alte substanțe sau grupe care nu aparțin niciunuia din grupul de mai sus (29).

Acestea sunt următoarele:

- Derivaţi sintetici de cocaină: dimetocaina şi 4-fluorotropocaina - efecte ușoare dopaminergice

- Derivaţii de ketamină şi fenciclidină (Angel Dust)

- Triptaminele naturale şi sintetice: psilocina şi bufotenin

- Mitragina: alcaloid conținut în frunzele arborelui asiatic Mytragina, cunoscut sub numele de Kratom sau Biak-Biak

- Lisergamida - alcaloid de tip ergot cu structură chimică şi acțiune asemănătoare cu LSD-25 și care se găsește în semințele plantei „Gloria dimineții“ (30).

\section{MANIFESTĂRI CLINICE ÎN INTOXICAȚIILE ACUTE CU SUBSTANȚE PSIHOACTIVE NOI}

Simptomele în intoxicațiile acute cu substanțe psihoactive noi sunt variate și polimorfe (tabel 1). Tabloul clinic cuprinde atât manifestări nespecifice, cât şi manifestări specifice, în funcție de tipul substanței sau modul de consum (33).

Manifestările nespecifice cuprind: somnolenţă, agitație, greață.

Manifestările specifice în funcție de tipul substanței consumate sunt: agitație, greață, uneori varsături, în cazul canabinoidelor sintetice, manifestări cardiovasculare, în special tahicardie și aritmii în cazul catinonelor sintetice, modificări ale percepției și stării de spirit în cazul halucinogenelor, convulsii ce pot realiza chiar stare de rău convulsiv în cazul piperazinelor, dar şi al catinonelor sintetice $(6,12)$.

În cazul consumului prin inhalație, pacientul va prezenta tuse, bronhoplegie, depresie respiratorie, în caz de ingestie dureri abdominale, vărsături, diaree, în caz de administrare injectabilă efecte sistemice instalate uneori rapid.

Debutul simptomelor depinde, de asemenea, de modul consumului. Astfel, în caz de inhalație sau fumat, acestea vor debuta imediat după consum, intensitatea maximă va fi la 20-30 de minute și vor persista 3-4 ore. În caz de ingestie, ele debutează la 30-60 de minute până la 6 ore, iar în caz de injectare se pot instala aproape imediat în minutele ce urmează administrării.

TABEL 1. Principalele manifestări clinice în intoxicațiile acute cu substanțe psihoactive noi

\begin{tabular}{|c|c|c|c|}
\hline $\begin{array}{l}\text { Nr. } \\
\text { crt }\end{array}$ & Categorie & $\begin{array}{l}\text { Forme de } \\
\text { prezentare }\end{array}$ & $\begin{array}{l}\text { Manifestări clinice ale } \\
\text { intoxicației }\end{array}$ \\
\hline 1. & $\begin{array}{l}\text { Canabinoide } \\
\text { sintetice }\end{array}$ & $\begin{array}{l}\text { Amestecuri de } \\
\text { plante }\end{array}$ & $\begin{array}{l}\text { Asemănătoare } \\
\text { canabisului, dar mai } \\
\text { severe } \\
\text { Agitație, psihoză } \\
\text { Palpitații } \\
\text { Vărsături incoercibile, } \\
\text { greață } \\
\text { Accident vascular, } \\
\text { convulsii, deces }\end{array}$ \\
\hline 2. & $\begin{array}{l}\text { Catinone } \\
\text { sintetice }\end{array}$ & $\begin{array}{l}\text { Pulbere albă sau } \\
\text { maronie } \\
\text { "Sare de baie” } \\
\text { „Îngrăşământ } \\
\text { de plante" sau } \\
\text { „reactivi chimici" }\end{array}$ & $\begin{array}{l}\text { Asemănătoare } \\
\text { amfetaminei, } \\
\text { metamfetaminei sau } \\
\text { cocainei, dar mai severe } \\
\text { Efecte } \\
\text { simpaticomimetice } \\
\text { Efecte cardiovasculare } \\
\text { severe: tahicardie, } \\
\text { aritmii, tulburări } \\
\text { circulatorii } \\
\text { Efecte neurologice - } \\
\text { convulsii } \\
\text { Hipertermie - tipic } \\
\end{array}$ \\
\hline 3. & $\begin{array}{l}\text { Halucinogene } \\
\text { naturale }\end{array}$ & $\begin{array}{l}\text { Plante (Salvia } \\
\text { divinorum) } \\
\text { Ciuperci }\end{array}$ & Efecte halucinogene \\
\hline 4. & Piperazine & Tablete, capsule & $\begin{array}{l}\text { Asemănătoare MDMA } \\
\text { (Ectasy) } \\
\text { Dureri epigastrice, } \\
\text { greață } \\
\text { Confuzie, tremor, } \\
\text { tulburări de somn } \\
\text { Iritabilitate, stare de rău } \\
\text { convulsiv } \\
\text { Sindrom serotoninergic: } \\
\text { anxietate, } \\
\text { migrenă, atacuri de } \\
\text { panică }\end{array}$ \\
\hline
\end{tabular}

\section{ANALIZE TOXICOLOGICE}

$\mathrm{Nu}$ există teste screening urinare sau de sânge pentru identificarea substanțelor psihoactive noi. $\mathrm{Cu}$ toate acestea, ele pot da reacții fals pozitive la testele screening urinare. De exemplu, unele catinone sintetice pot da reacții fals pozitive pentru metamfetamine, având în vedere structura asemănătoare $(2,34)$.

Unii compuși pot fi identificați numai în laboratoare înalt specializate dotate cu aparatură performantă (35).

Identificarea substanțelor psihoactive noi este foarte dificil de efectuat din cauza varietăţii mari a 
structurii chimice, dar mai ales din cauza schimbărilor rapide şi continue a structurii acestora în laboratoarele ilicite, în fiecare an fiind raportate în jur de 50 de structuri noi $(6,12)$.

\section{DIAGNOSTICUL POZITIV}

Prin urmare, diagnosticul pozitiv de intoxicaţie acută cu substanțe psihoactive noi se va stabili exclusiv pe baza anamnezei și a examenului clinic.

\section{TRATAMENT}

Tratamentul este nespecific şi simptomatic, incluzând terapie de reechilibrare hidro-electrolitică şi acido-bazică, monitorizare cardiacă, sedare etc.

\section{CONSUMUL CRONIC}

Consumul cronic de substanțe psihoactive noi poate determina tulburări severe la nivelul întregului organism. Au fost descrise tulburări cardiovasculare: tulburări de ritm, hipotensiune arterială sau hipertensiune arterială, tulburări respiratorii sau digestive. O atenție deosebită trebuie acordată tulburărilor neurologice şi psihice care cuprind: încetinirea mecanisme- lor psihice complexe (capacitatea de învățare, de concentrare şi memorie), afectarea luciditații mentale și coordonării psihomotorii care sunt implicate în activităti complexe cum ar fi conducerea automomobilului $(36,37)$. Au fost descrise chiar tulburări psihice de tip schizofrenie la persoanele ce au o predispoziție în acest sens (38).

Consumul cronic va conduce în timp la fenomenul de toleranță (necesitatea expunerii la cantități din ce în ce mai mari de substanță pentru a obține același efect obținut inițial la doze mai mici) dar și la fenomenul de dependență atât psihică cât și fizică $(39,40)$.

\section{CONCLUZII}

Consumul ocazional care poate duce la intoxicații acute sau consumul cronic de substanțe psihoactive noi reprezintă o problemă importantă de sănătate ocupând un loc care nu trebuie neglijat în patologia adolescenților şi tinerilor.

Analizănd caracteristicile acestor substanțe de la modul de producere, structura chimică şi până la rapiditatea cu care sunt introduce și schimbate, se poate spune că singura modalitate de a preveni consumul este o educație susținută și permanentă în școli și licee.

Conflict of interest: none declared Financial support: none declared

\section{BIBLIOGRAFIE}

1. New psychoactive substances (NPS) | www.emcdda.europa.eu. www. emcdda.europa.eu/topics/nps_en- acces septembrie-

2. Simon Gibbons. Legal Highs - novel and emerging psychoactive drugs: A chemical overview for the toxicologist. Clin Tox, 50(1), 15-24.

3. Sumnall HR, Evans-Brown M, McVeigh J. Social, policy, and public health perspectives on new psychoactive substances. Drug Test. .2011;3: 515-523.

4. Synthetic cannabinoids in Europe / www.emcdda.europa.eu. www. emcdda.europa.eu/topics/pods/synthetic-cannabinoids_en.

5. Cooper DZ. Adverse Effects of Synthetic Cannabinoids: Management of Acute Toxicity and Withdrawal. Curr Psychiatry Rep. 2016; 18(5): 52

6. Highlighs from the EU Drug Market Report for policy and practice, EMCDDA, EUROPOL, Lisbon, November 2019.

7. US Department of Justice National Drug Intelligence Center Situation report: Synthetic cathinones (bath salts) - an emerging domestic threat 2011. Available from: http://www.justice.gov/archive/ndic/ pubs44/44571/44571p.pdf.

8. Tyndall JA, Gerona R, De Portu G et al. An outbreak of acute delirium from exposure to the synthetic cannabinoid AB-CHMINACA. Clin Toxicol. 2015;53(10):950-956.

9. Phillips J, Lim F, Hsu R. Synthetic cannabinoid poisoning. A growing health concern. Nursing. 2019;46(11):34-41.

10. Davis C, Boddington D. Teenage cardiac arrest following abuse of synthetic cannabis. Heart Lung Circ. 2015;24:e162-e163.

11. Takematsu M, Hoffman RS, Nelson LS et al. A case of acute cerebral ischemia following inhalation of a synthetic cannabinoid. Clin Toxicol. 2014;52:973-975.

12. EMCDDA | Synthetic cathinones profile (chemistry, effects). www. emcdda.europa.eu/publications/drug-profiles/synthetic-cathinones.
13. Riley $\mathrm{AL}$, Nelson $\mathrm{KH}$ et al. Abuse potential and toxicity of the synthetic cathinones (i.e., "Bath salts"). Neurosci Biobehav Rev. 2019. pii: S0149-7634(18)30319-1.

14. European Drug Report 2019 -Trends and Developments, EMCDDA, Lisbon, Portugal, 2019: 56-62.

15. Spiller HA, Ryan ML, Weston RG et al. Clinical experience with and analytical confirmation of "bath salts" and "legal highs" (synthetic cathinones) in the United States. Clin Toxicol. 2011;49:499-505.

16. Dargan PI, Albert S, Wood DM. Mephedrone use and associated adverse effects in school and college/university students before the UK legislation change. QJM. 2010;103(11):875-879.

17. Centers for Disease Control and Prevention (CDC) Emergency department visits after use of a drug sold as "bath salts" MMWR Morb Mortal Wkly Rep. 2011;60(19):624-627.

18. Dargan P, Sedefov R, Gallegos A et al. The pharmacology and toxicology of the synthetic cathinone mephedrone (4-methylmethcathinone). Drug Test. Analysis. 2011: 454.

19. Sammler EM, Foley PL, Lauder GD, Wilson SJ, Goudie AR, O'Riordan JI. A harmless high? Lancet. 2010;376(9742):742.

20. Coppola M, Mondola R. Synthetic cathinones: Chemistry, pharmacology and toxicology of a new class of designer drugs of abuse marketed as "bath salts" or "plant food". Toxicol Lett. 2012;211(2):144149.

21. Hohmann N, Mikus G, Czock D. Effects and Risks Associated with Novel Psychoactive Substances. Mislabeling and Sale as Bath Salts, Spice, and Research Chemicals. Dtsch Arztebl Int. 2014; 111(9): 139-147.

22. Prosser JM, Nelson LS. The toxicology of bath salts: A review of synthetic cathinones. J Med Toxicol. 2012;8(1):33-42. 
23. EMCDDA - Hallucinogenic mushrooms profile (chemistry, effects...) www.emcdda.europa.eu/publications/drug-profiles/mushrooms.

24. Martins PB, Freeman S, Alder JF et al. Profiling psychoactive tryptamine-drug synthesis by focusing on detection using mass spectrometry. TrAC. 2010;29(4):285-296.

25. Williams RH, Erickson T. Evaluating Hallucinogenic orPsychedelic Drug Intoxicationin an Emergency Setting. Lab Med. 2000; 31(7):394-401.

26. Gibbons S. 'Legal Highs' - Novel and emerging psychoactive drugs a chemical overview for the toxicologist. Clin. Toxicol. 2012;50(1):15-24.

27. Tittarelli R, Mannocchi G, Pantano F et al. Recreational Use, Analysis and Toxicity of Tryptamines. Curr Neuropharmacol. 2015; 13(1): 26.46.

28. EMCDDA - BZP/piperazines profile (chemistry, effects, other...) www. emcdda.europa.eu/publications/drug-profiles/bzp.

29. King LA, Kicman AT. A brief history of 'new psychoactive substances' Drug Test. Analysis. 2011;3: 401-403.

30. Rosenbaum CD, Carreiro SP, Babu KM. Here Today, Gone Tomorrow... and Back Again? A Review of Herbal Marijuana Alternatives (K2, Spice), Synthetic Cathinones (Bath Salts), Kratom, Salvia divinorum, Methoxetamine, and Piperazines. J Med Toxicol. 2012; 8(1): 15-32.

31. Schep LJ, Slaughter RJ, Vale AJ, et al. The clinical toxicology of the designer "party pills" benzylpiperazine and trifluoromethylphenylpiperazine, Clin Tox. 2011;49(3):131-141

32. Juszczak GR, Swiergiel AH. Recreational Use of D-Lysergamide from the Seeds of Argyreia Nervosa, Ipomoea Tricolor, Ipomoea Violacea, and Ipomoea Purpurea in Poland. J Psychoactive Drugs. 2013; 45(1):79-93.

33. Elliott S, Evans J. A 3-year review of new psychoactive substances in casework. Forensic Science International. 2014;243:55-60.

34. Elliott S. Cat and mouse: The analytical toxicology of designer drugs. Bioanalysis 2011;3: 249-251.

35. Dignam G, Bigham C. Novel psychoactive substances: A practical approach to dealing with toxicity from legal highs. BJA Education. 2017;17(5): 172-177.

36. Graziano S, Orsolini L, Concetta Rotolo M et al. Herbal Highs: Review on Psychoactive Effects and Neuropharmacology. Current Neuropharmacology. 2017;15: 750-761.

37. Darke S, Kaye S, Ketin RMC et al. Major physical and psychological harms of methamphetamine use. Drug Alcohol Rev 2008; 27: 253-62.

38. Miliano C, Serpelloni G, Rimondo C et al. Neuropharmacology of New Psychoactive Substances (NPS): Focus on the Rewarding and Reinforcing Properties of Cannabimimetics and Amphetamine-Like Stimulants. Front Neurosci. 2016;10(153):1-21.

39. Lopes GM, Araujo Nobrega B, Del Prette G et al. Use of psychoactive substances by adolescents:current panorama. Brazilian J Psychiatry 2013;35:S51-S61.

40. Scherbaum N, Schifano F, Bonnet U. New Psychoactive Substances (NPS) - a Challenge for the Addiction Treatment Services. Pharmacopsychiatry. 2017.50(3):116-122. 